\title{
Effects to Improve the Quality of Life: Color, Performance and Protection from Ciba Specialty Chemicals
}

\author{
Werner Rutsch* and Michael A. Cech
}

\begin{abstract}
Ciba Specialty Chemicals creates effects to improve the quality of life. Building on its technical competencies, the company has developed major innovative product groups that provide color, performance and protection. Antioxidants and light stabilizers protect plastics, coatings, photographic pictures and wood from degradation induced by sunlight, air, ozone, heat, fire and mechanical stress. UV absorbers protect human skin from sunburn and photo-induced ageing. Pigments and dyes add beautiful colors to objects of everyday life, serve as recording media for optical information storage on digital versatile discs (DVDs) and are used as color filters in liquid crystal displays (LCDs). Effect pigments allow creation of color and visual effects by interference. Polymeric flocculants are essential components for solid-liquid separation processes in wastewater treatment and paper production. Photolatent catalysts are key components for light-induced polymerization reactions. New sterically hindered $\mathrm{N}$ alkoxyamines are initiators for nitroxide mediated radical polymerization (NMP) reactions leading to new pigment dispersants with well-defined molecular weights and narrow molecular weight distribution. New $\mathrm{N}$-acyloxyamines are proposed as peroxide substitutes for controlled degradation of high molecular weight polypropylene. A new clarifier can be used to produce polypropylene with enhanced transparency and excellent mechanical properties. Progress in enabling sciences such as nanotechnology and biotechnology together with new technologies entering the markets will offer outstanding opportunities for new developments in specialty chemicals.
\end{abstract}

Keywords: Colorants · Photolatent catalysts $\cdot$ Polymeric flocculants $\cdot$ Stabilizers $\cdot$ UV protection

\section{Introduction}

Ciba Specialty Chemicals develops, manufactures and markets products present in many items you see and use each and every day. Ciba pigments and dyes are essential for beautiful color effects. Antioxidants and light stabilizers protect polymers from degradation during processing and prevent them from aging during use. UV absorbers provide protection from harmful effects of UV light for car coatings as well as human skin. Polymeric flocculants make municipal and industrial effluent treatment, paper making and mining for coal, oil, precious

${ }^{\star}$ Correspondence: Dr. W. Rutsch

Ciba Specialty Chemicals Inc.

Corporate Technology Office

Klybeckstrasse 141

$\mathrm{CH}-4002$ Basel

Tel.: +41616363684

Fax: + 41616365774

E-Mail: werner.rutsch@cibasc.com metals and ores more efficient. Photolatent polymerization catalysts enable the environmentally friendly curing of coatings, allow the production of electronic resists for laptops and the production of printing plates. Even mobile phone screens, DVDrecordables, transparent packaging materials and, last but not least, personal care products benefit from Ciba's long standing experience and competency in specialty chemicals. This is reflected in Ciba's official vision: We create effects to improve the quality of life.

The roots of Ciba Specialty Chemicals date back to 1758 when J.R. Geigy Ltd. began trading in chemicals and dyes. Today, Ciba employs 15,000 people around the world, generates sales of over CHF 6 billion and invests around CHF 270 million in research and development per year. Markets and industries served include plastics, coatings, paper, printing, packaging, automotive, construction, electronics, water treatment, agriculture and home \& personal care.

This article describes how Ciba uses its extensive technical competencies in stabilization, protection, color, photolatent catalysts and solid-liquid separation (floccula- tion), to name just the most important ones, to develop major product groups of today's business. It also presents some examples of recent product innovation and indicates some future trends of research.

\section{Leveraged Technical Core Competencies and Strong Technology Platforms}

\subsection{Protection and Stabilization from Synthetic Polymers to Human Skin}

Organic materials, both of synthetic and natural origin, are intrinsically unstable and undergo changes in appearance and physical properties when exposed to sunlight, air, ozone, heat, fire and mechanical stress: 'aging' and 'degradation' phenomena occur. Chemical reactions with oxygen, damage induced by UV-light and chain-scission of the organic backbone under heat, fire, and mechanical stress (during processing) are the root causes of degradation and free radical chain reaction mechanisms play a dominant role. Stabilizers for inhibiting or slowing down degradation were prerequisite for today's extensive commercial use 
of synthetic polymers [1], paints, and coatings [2].

Breakthroughinnovations in the polymer industry, mainly the discovery by Ziegler and Natta of heterogeneous catalysts which allow the low-pressure polymerization of olefins, started a tremendous growth story for this industry in the 1950s. In parallel, and in close technical partnerships, Ciba Specialty Chemicals has played a pioneering role in developing high-performance stabilizers that reached the market in the early 1960s. The fundamental symbiosis between the additives and polymer industries greatly expanded the market for polyolefins, which in turn led to stronger demand for even better stabilizers [3].

Also, for the long-lasting exterior application requirements of paints and coatings, light stabilizers are indispensable. Again, Ciba Specialty Chemicals has played a key role in these industries by making high-performance stabilizers available that allowed, for example in the automotive industry, implementation of the so-called two-coat technology approach for cars, where a clear coating is applied over the colored basecoat to achieve optimal durability and appearance. Today, Ciba is the largest worldwide producer of products providing protection and stabilization.

Stabilizers are chemical substances that are added to organic materials (mainly synthetic polymers) in small amounts, typically up to $2 \mathrm{wt} \%$. Major stabilizer classes are antioxidants and light stabilizers (Fig. 1). Antioxidants are capable of trapping emerging free radicals appearing in the degradation process, by donating a hydrogen radical $\left(\mathrm{Ciba}^{\circledR}{ }^{\circledR}\right.$ IRGANOX $^{\circledR}$ 1010, a hindered phenol-based product, and $\mathrm{Ciba}^{\circledR}$ IRGANOX $^{\circledR} 5057$, an aromatic amine) or decomposing peroxides that have been generated in the substrate from radicals trapping dissolved oxygen $\left(\mathrm{Ciba}^{\circledR}\right.$ IRGAFOS $^{\circledR}$ 168, a phosphite-based product). Light stabilizers are classified as UV absorbers if they are capable of absorbing UV light before it can initiate the damaging reactions on the substrate $\left(\mathrm{Ciba}^{\circledR}{ }^{\circledR}\right.$ TINUVIN $^{\circledR} 384$, a hydroxyphenyl-benzotriazole, or $\mathrm{Ciba}^{\circledR}$ TINUVIN $^{\circledR} 405$, a hydroxyphenyl-triazine) or as a hindered amine light stabilizer (HALS) if they intercept radicals during polymer degradation $\left(\mathrm{Ciba}^{\circledR}{ }^{\circledR}\right.$ TINUVIN $^{\circledR}$ $770 / 123$ and $\mathrm{Ciba}^{\circledR}$ CHIMASSORB $\left.{ }^{\circledR} 944\right)$. If emerging radicals and peroxides are not efficiently eliminated in the substrate, rapid degradation will occur in an autocatalytic degradation process.

The linking and leveraging across various markets and industries of these technology platforms is demonstrated by the fact that products shown in Fig. 1 and derivatives thereof are, as already mentioned, not only used to protect and stabilize plastics and coatings. In addition, if such stabili-

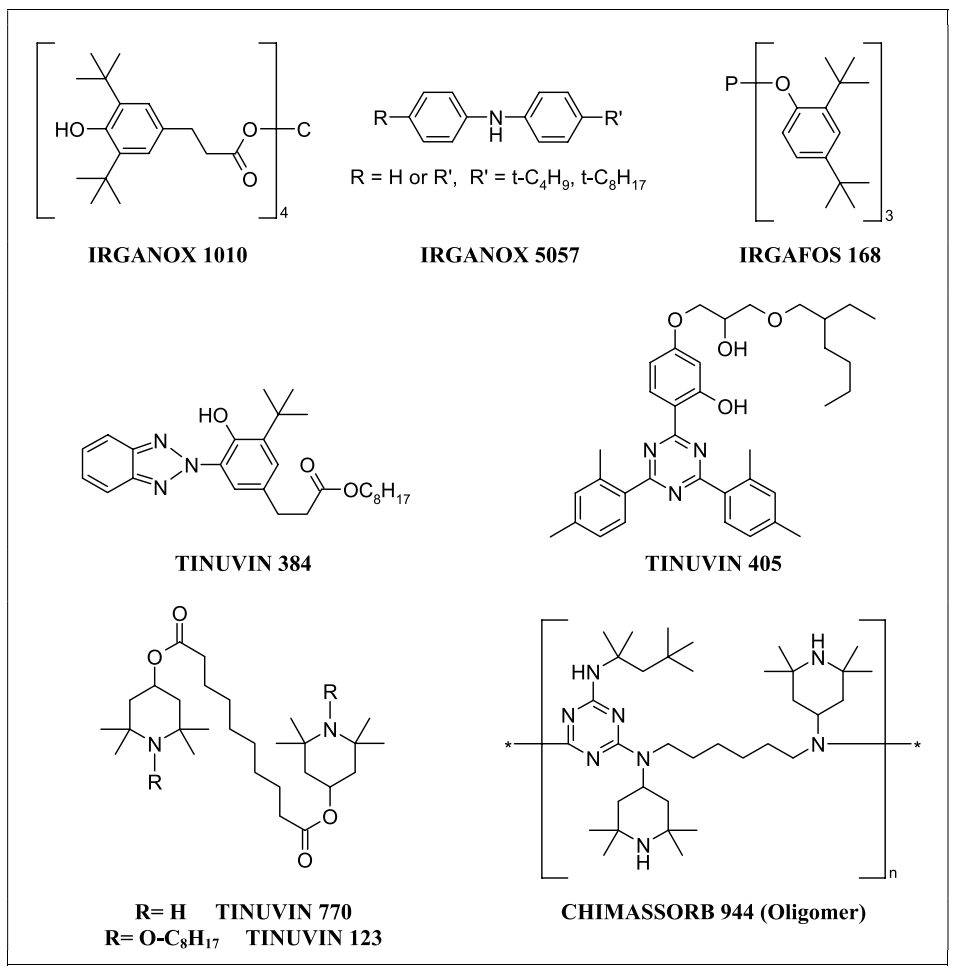

Fig. 1. Typical examples of commercial antioxidants and light stabilizers

zers are added to lubricating oils [4], they perform better and longer. Also, the fading of photographic pictures is delayed considerably. A nitroxide derivative of the HALS family $\left(\right.$ Ciba $^{\circledR}$ LIGNOSTAB $^{\circledR}$ 1198) inhibits lignin photo-oxidation [5], ensuring that wood keeps its natural color and attractive appearance. The N-alkoxy-HALS derivative $\left(\right.$ Ciba $^{\circledR}$ FLAMESTAB ${ }^{\circledR}$ NOR 116) shows efficacy as a halogen-free flame retardant [6]. The most apparent use for end consumers of this entire array of stabilizer technologies may be in cosmetics: cosmetic products remain fresh for a longer time period if containers and the contents of cosmetics contain appropriate stabilizers [7] Also, UV absorbers $\left(\mathrm{Ciba}^{\circledR}\right.$ TINOSORB $^{\circledR}$ $\mathrm{M}$ and TINOSORB ${ }^{\circledR} \mathrm{S}$ ) are key ingredients in sunscreens that protect human skin from sunburn and photo-induced ageing [8] (Fig. 2 and Section 4).

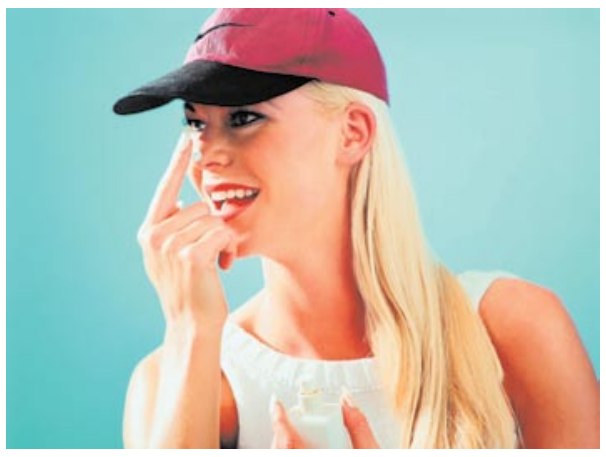

Fig. 2. Ciba's UV absorbers used in sun creams provide highly effective protection against sunburn
Besides new and improved stabilizers, the portion of Ciba Specialty Chemicals' $\mathrm{R} \& \mathrm{D}$ portfolio that is oriented towards the plastics industry is being focused on new products and effects enabling an even broader use of polymers, for example clarifiers (see Section 3.3), antistatic additives, surface modifiers, oxygen scavengers, and bio-protection.

\subsection{Bringing Color into Our Lives}

We learn how to choose and combine colors in the very early stages of our childhood. We are influenced by colors, which, in turn, are often linked to emotions. As consumers, we possess astonishing sensitivity when it comes to handling colors, largely influenced by preconceived images or ideas.

In a study conducted by one of the leading ink makers [9], it has been discovered that telephone listings printed in color can increase call rates by $44 \%$, while invoices produced in color can improve payment response by up to $30 \%$. It has also been found that people are $55 \%$ more likely to pick up a piece of full color mail first and that color can improve brand recognition by as much as $80 \%$ ! Color makes a positive difference.

'Colorants' are either organic or inorganic materials that add color to an object by the selective absorption and/or scattering of light. Colorants are divided into mainly two classes, pigments and dyes, by physical characteristics rather than chemical composition. Pigments, by definition, are organic or inorganic, colored, white or black materials which are practically insoluble in the 
medium in which they are incorporated. Dyes, unlike pigments, dissolve in the medium of their application [10].

Ciba Specialty Chemicals, dating back to the earliest days of its predecessor companies in the 18th century, has been producing colorants and offering them to various end users. Despite recently exiting from dyes for textile applications (sale of Textile Effects business to Huntsman Corporation in 2006), Ciba continues to play an important role in bringing colors into our life. A broad range of pigments and dyes are offered for various applications in coatings, plastics, inks, paper, wood, imaging materials (photographic toners), and personal care (coloration of hair).

But pigments are not only used to add decorative color. An example where pigments from Ciba Specialty Chemicals play an important role as 'functional colors' is in liquid crystal displays (LCD) used for television sets, mobile phones, digital cameras, gaming consoles and personal computers. These displays deliver images using millions of tiny triplets of red, blue and green color filters made of pigments. Each color filter is switched on or off electronically, and each triplet combines into one dot of an on-screen shade. Like the daubs of color in an impressionist painting, the dots form an image when viewed together. Ciba pigments (Ciba ${ }^{\circledR}$ IRGAPHOR ${ }^{\circledR}$ product line) are used today widely in the manufacturing of these color filters. The highly engineered pigment particles in the nanometer scale ensure best transmission and absorption of the right color. Ciba photoinitiators are used both to form the color triplets and to cure the black matrix resin surrounding the triplets, which gives improved color contrast. Application testing needs to be done in a clean room to exclude dust (Fig. 3). Photoinitiators will be described in Section 2.4.

Dyes are not only used for decorative applications. For example, different classes of Ciba Specialty Chemicals dyes $\left(\mathrm{Ciba}^{\circledR}\right.$ IRGAPHOR $^{\circledR}$ product line) are used as recording media in the manufacturing of compact discs (CD-R) and digital versatile discs (DVD-R). The dye is the essential chemical component allowing the 'writing' or 'burning' of the information by means of a laser beam onto the disc. These discs help all of us to digitally store information, something with which we have gotten so used to in today's life, and something that we would not normally relate to an achievement in chemistry.

Chemistry managed by Ciba Specialty Chemicals to produce the various colorants is based mainly on organic molecules or metal complexes thereof, such as phthalocyanines, naphthols, benzimidazolones, azo condensates, diarylides, anthraquinones and perinones, quinacridones, isoindolinones, isoindolines, dioxazines, perylenes,

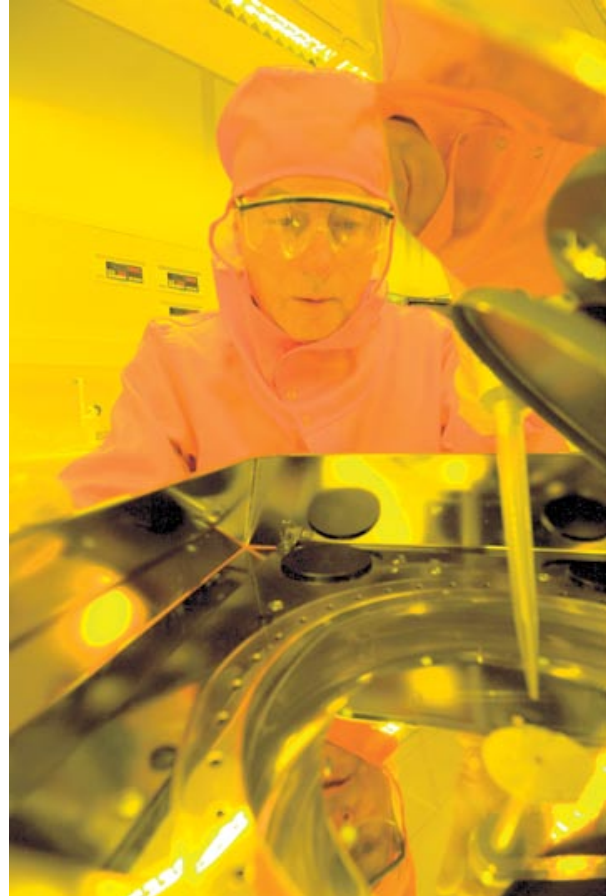

Fig. 3. Application testing of pigments and

and diketo pyrrolo pyrroles (DPP). Some of these colorants, for example DPP pigments [11] and isoindolinones [12], are indeed the fruits of Ciba's innovation efforts (Fig. 4).

In colorants, the chromophore, which is defined by the chemical structure, is responsible for imparting the color. However, when it comes to pigments, final color properties result from interactions between three key features: chemical structure, size and shape as well as surface treatments of the particles. Careful optimization of these key features is required to produce and offer a range of pigments that meet the requirements of the market.

Surface treatment determines the dispersibility of the small pigment particles to yield a colloidal system. The process, in itself, involves the stages of wetting, aggregate breakdown and separation as well as dispersion stabilization of the pigment particles. Ciba Specialty Chemicals offers a range of polymeric dispersants $\left(\mathrm{Ciba}^{\circledR}\right.$ EFKA $^{\circledR}$ range) that can be suitably employed for a given pigment. New and improved dispersants produced by controlled free radical polymerization are described in Section 3.1

Diketo Pyrrolo Pyrroles (DPP) photoinitiators for LCDs

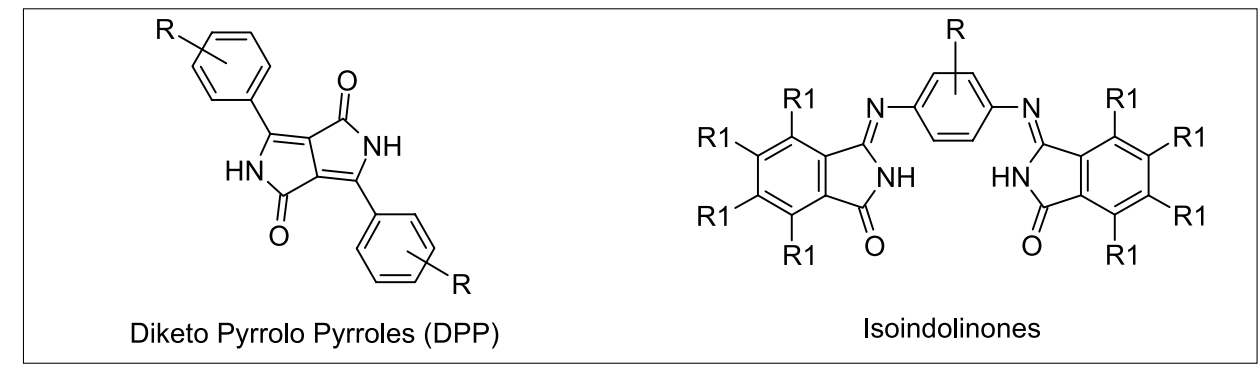

Producing various effects based on creatively managing light is and will remain a core competency of Ciba. New horizons of producing color effects are opened up by so-called 'effect pigments' allowing the generation of 'physical colors' based on interference phenomena as described in Section 3.4

\subsection{Polymeric Flocculants for Efficient Solid-Liquid Separation}

During the late 1960s to early 1970s, polymeric flocculants became established as essential components for use in many of the solid-liquid separation processes operated by industry [13], mainly in wastewater treatment and paper production. This was made possible by the increased commercial availability of key building block chemicals (i.e. monomers) namely acrylamide, acrylic acid, and a cationic species, [2-(acryloyloxy)ethyl]trimethylammonium chloride. The manufacturing process involves chain growth polymerization reactions. Mixtures of monomers can be used to form random copolymers. Typical molecular weights range from 5 to 10 million or even more. The reaction achieves a very high degree of conversion such that residual monomer levels are routinely well below $1,000 \mathrm{ppm}$. Throughout the last 40 years, polymer chemists have striven to develop a better understanding of how product recipe and manufacturing conditions can be controlled and varied to enhance the performance and cost effectiveness in use. The improvements have been dramatic, allowing major improvements in the type, design and efficiency of machinery used in such separation processes. Today, few if any of these operations can work effectively without flocculants, making important contributions to increased efficiency, allowing costs to consumers to be more moderate and protecting the environment.

\subsubsection{Municipal and Industrial Effluent and Sludge Treatment and Disposal}

Today, most wastewater treatment plants rely on one or more biological purification steps, the output of which is a sludge containing only a few percentage points of solid matter. Cationic acrylamide-based flocculants (containing up to $90 \mathrm{wt} \%$ of cationic monomer) of the

Fig. 4. Structures of DPP and Isoindolinone pigments 
$\mathrm{Ciba}^{\circledR} \mathrm{ZETAG}^{\circledR}$ flocculants range are particularly well suited to treating such sludge, as they promote rapid agglomeration of solids suspended in water. High-speed solid bowl centrifuges are commonly used to separate flocculated solids from the water phase, but the extreme shear and mixing conditions in this sort of equipment requires exceptional robustness and durability from the polymer molecule in solution. The deliberate use of trace quantities of chain transfer reagents and cross-linking monomers in the manufacturing process can create products with a carefully optimized polymer chain architecture and molecular weight distribution ideally suited to such conditions. This leads not only to an aqueous phase ready for disposal into watercourses but also to a sludge 'cake' with significantly higher solids content, resulting in lower unit disposal costs. This helps to protect our environment at a lower cost.

\subsubsection{New Application in Extractive Industries}

Mining for coal, ores, precious metals and oil from tar sand involves mined material being slurried into large volumes of water to ensure that the separation of desired raw material and recovery processes operate effectively. Afterwards, vast quantities of 'tailings' (water contaminated with fine particles of sand, silt and clay) remain for disposal. Critical operating requirements are quick and efficient recovery of water for re-use as well as a fast and total consolidation of the solids to maximize the efficiency of the tailings dam (which can cover several $\mathrm{km}^{2}$ ) as well as its speedy rehabilitation. A wide range of anionic flocculants based on acrylic acid/acrylamide or acrylamide/2acrylamido-2-methyl-1-propanesulphonic acid co-polymers $\left(\mathrm{Ciba}^{\circledR} \mathrm{MAGNAFLOC}^{\circledR}\right.$ range), is routinely used to flocculate these inorganic particles, typically using large settlement tanks or thickeners (Fig. 5). Settling speed, solids content of the underflow slurry and its rheological properties (such as yield stress) determine thickener performance. These are strongly influenced by the type of polymer employed (charge density, molecular weight distribution and branching density). The vast amount of material requiring treatment and disposal (up to 100,000 tonnes/day) not only needs optimal product design but also in-depth application know-how, including post-thickener treatments, to optimize floc strength/structure and so provide a dramatic shortening of the timescale (from many years to several months) over which the tailings dam site is fully rehabilitated. This technology, sold under the trade name of $\mathrm{Ciba}^{\circledR}$ RHEOMAX $^{\circledR}$, has further improved the efficiency of extracting oil from tar sand and the mining of both precious and commodity metals, and has brought significant environmental

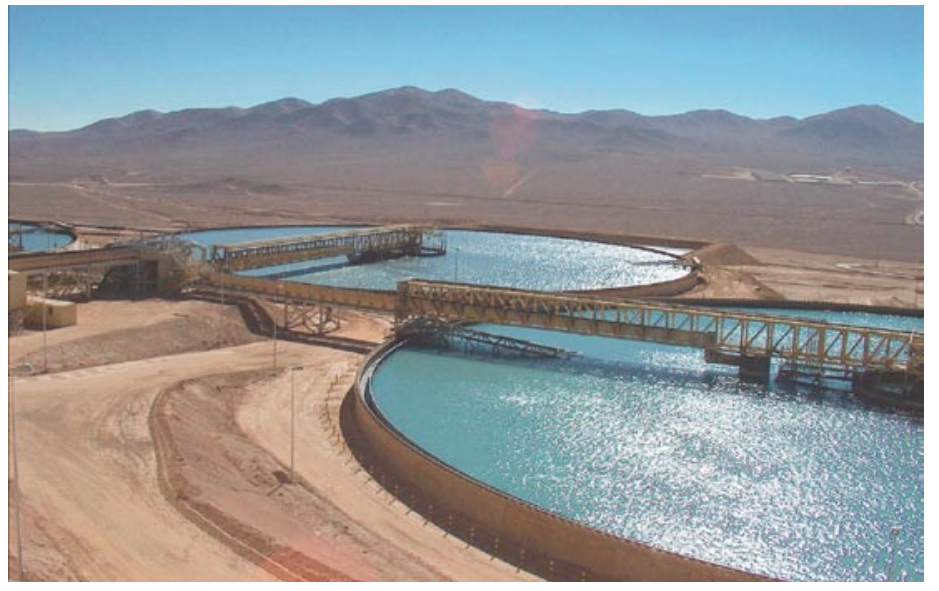

Fig. 5. Tailings thickener tanks

improvements to mining operations in general.

\subsubsection{Making Paper Even Faster}

The initial stage of the papermaking process also involves the need for an incredibly efficient solid-liquid separation process. Wood fibers, mineral fillers and other minor ingredients are mixed to form a very dilute slurry $(<1 \%$ solids content) in water which is transferred onto a fine wire mesh moving at high-speed (up to $2,000 \mathrm{~m} / \mathrm{min}$ ) through the paper machine. Retention (of fibers, fines, and fillers), drainage, and formation (the desired consolidation and layering of fiber and filler), is controlled by carefully balanced multi-component chemical programs $\left(\mathrm{Ciba}^{\circledR} \mathrm{HYDROCOL}^{\circledR}\right.$ and $\mathrm{Ciba}^{\circledR}$ TELIOFORM $^{\circledR}$ ) that follow clearly defined orders of addition [14][15]. Ingredients that are used include low to high molecular weight cationic or anionic linear polymers (for charge control as well as for primary flocculation), anionic polymeric microparticles (core/shell structures), and inorganic microparticles (e.g. bentonite, silica) [16] Without such sophisticated polymer components, today's paper machine could not achieve the enormous efficiency seen today and prices for paper would have to be even higher without these advancements.

\subsection{Photolatent Polymerization Catalysts: Curing on Demand at the Speed of Light}

Industrial applications of photolatent polymerization catalysts ('photoinitiators') started in the early 1970 s with the photoinduced radical polymerization ('radiation curing') of coatings, inks, or adhesives on flat surfaces of wood, paper, metal and plastic. In practical terms, this means that wet coatings are fully dried in split seconds by simply exposing them to a flash of light. By structuring the incident light through a photomask, placed between the light source and the substrate, light areas (where curing will occur) and dark areas (where no curing occurs) are differentiated, and the imaging of electronic resists and the production of relief images for printing plates became reality. The principle of photolatency is straightforward: the incident light is absorbed by the photolatent catalyst to reach an excited state from which reactive intermediates are produced. In most cases, these intermediates are radicals capable of adding to vinylic or acrylic double bonds, thereby initiating radical polymerizations. Cationic, anionic or basic intermediates, which are reactive enough to initiate the respective polymerization reactions, are also available [17]. Today, light-induced free radical polymerization, particularly using UV light as the light source ('UV curing'), is a well-established industrial process.

Ciba Specialty Chemicals played a pioneering role in developing appropriate photoinitiators [18][19]. Major classes of photolatent catalysts are shown in Fig. 6. Photoinitiators producing radicals via $\alpha$-cleavage mechanisms are benzil-ketals $\left(\mathrm{Ciba}^{\circledR}\right.$ IRGACURE $^{\circledR}$ 651), $\alpha$-hydroxyacetophenones $\left(\mathrm{Ciba}^{\circledR}{ }^{\circledR R G A C U R E}{ }^{\circledR} 184\right)$, $\alpha$-amino-acetophenones $\left(\mathrm{Ciba}^{\circledR} \quad\right.$ IRGACURE $^{\circledR} 907$ and 369), acylphosphine oxides (Ciba ${ }^{\circledR}$ DAROCUR ${ }^{\circledR}$ TPO), bis-acylphosphine oxides $\left(\mathrm{Ciba}^{\circledR}\right.$ IRGACURE $^{\circledR}$ 819) and O-acyl-oximes (Ciba ${ }^{\circledR}$ IRGACURE® OXE02), which was tailor-made for color filter applications in LCDs. Typical examples of photolatent strong acids are diaryliodonium salts $\left(\mathrm{Ciba}^{\circledR}\right.$ IRGACURE $^{\circledR}$ 250) for the curing of epoxy resins, while photoacid generators $\left(\mathrm{Ciba}^{\circledR}\right.$ IRGACURE $^{\circledR}$ PAG 203) are used in microlithograpy. Photobase generators of structure $\mathbf{1}$ are a novel class of photolatent catalysts in an advanced development phase.

The commercially available products shown in Fig. 6 allow a broad range of typical applications where thin and unpigmented layers are cured on flat substrates or regular objects such as optical fibers. Substantial progress has also been achieved in curing thicker layers, where light penetra- 


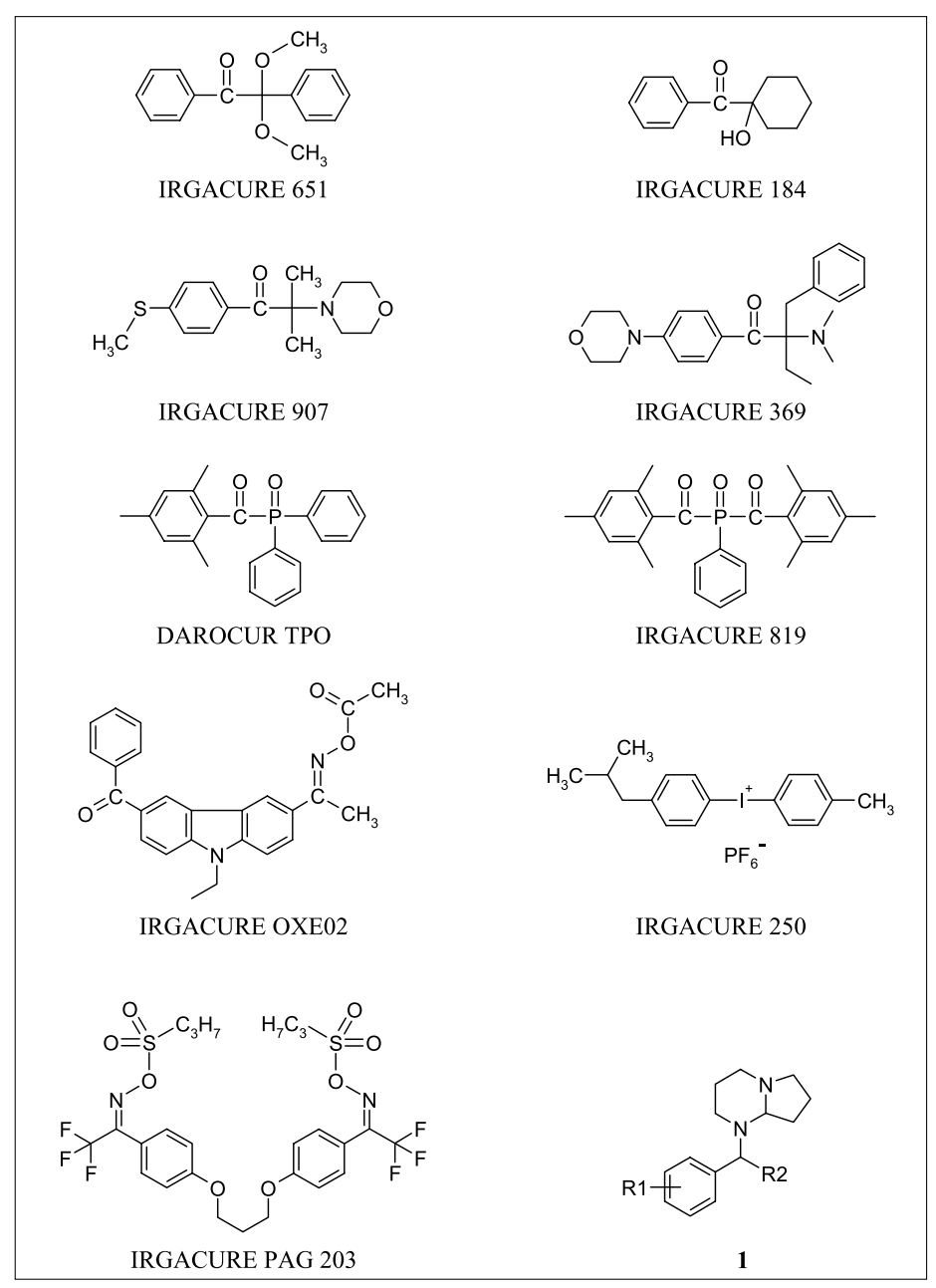

Fig. 6. Typical examples of radical photoinitiators, photoacid and photobase generators.

tion to the bottom of the layer is limited (Lambert-Beer's law for light absorption), and in pigmented systems where light absorption of the pigment competes with the photoinitiator for the available light.

A remaining challenge is the radiation curing of coatings on three-dimensional objects, for example car bodies, where UVlight induced curing would again offer big ecological advantages (no solvent emission) and allow higher quality, speed and efficiency in automated production lines compared to thermal curing. But, the lack of curing in shadow areas was an insurmountable technical hurdle that prevented commercial application to date.

A breakthrough has now been achieved with UV-plasma curing [20]. In this new and patented technology, the car with the wet paint is placed in a plasma chamber that is then filled with process gases like nitrogen, helium and/or argon. The plasma is subsequently ignited with a strong microwave. The produced plasma spontaneously spreads throughout the chamber and penetrates even cavities and undercuts of the car body. Collisions between highly reactive species in the plasma result in the formation of excited species, which are deactivated by the emission of light (the same principle is plasma technology specialists (Roth \& Rau Oberflächentechnik AG, Hohenstein-Ernstthal), equipment engineers (Dürr Systems $\mathrm{GmbH}$, Stuttgart) and Ciba as the specialty chemicals provider. The successful test runs have triggered strong interest in the automotive industry and commercial implementation is envisaged for the near future.

\section{Recent Examples of Innovation by Ciba Specialty Chemicals}

\subsection{Industrial Realization of Living Radical Polymerization}

Today, about one-half of world polymer production is based on radical polymerization. This is due to several unique factors, for example the broad availability of acrylic and vinylic monomers as well as 'forgiving' reaction conditions that also tolerate trace amounts of oxygen or monomer stabilizers. Besides homopolymers, copolymers with unique material properties can also be made. However, advanced materials - such as polymers with well-defined molecular weight and narrow molecular weight distribution, defined chain end functionalities, block-, comb- or star copolymers, to name just a few - are not accessible via conventional radical polymerization. But, there is a clear industrial need for advanced materials, for example for tailor-made pigment dispersants. The fact that such materials were only accessible via sophisticated nonradical living polymerization techniques [21] was a limiting factor for commercial development in the past.

Significant progress, however, has been achieved over the last ten years in living radical polymerization such as atom transfer radical polymerization (ATRP), reversible addition fragmentation chain transfer (RAFT) or nitroxide mediated radical polymerization (NMP). These methods are

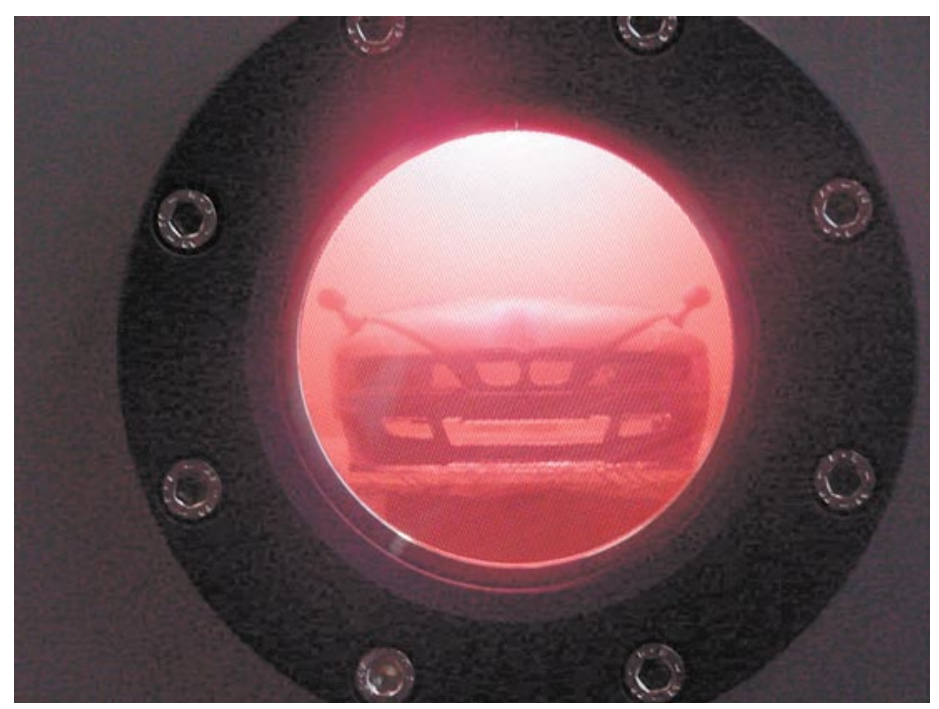

Fig. 7. UV PlasmaCure ${ }^{\mathrm{TM}}$ technology allows curing in shadow areas of a car body 
now widely used at the laboratory scale to prepare polymers with complex architecture [22]. However, up-scaling to multi-tonne industrial scale still faces important challenges. For example, removal of the copper catalyst and incorporation of the halogen from the initiator into the polymer are issues for ATRP, whereas RAFT polymers can have undesired color or smell caused by the sulfur-containing RAFT agent. The NMP is metal- and sulfur-free and, hence $a$ priori, better suited for industrial use. The remaining challenges are the availability of nitroxide-derived alkoxyamine initiators and the large amount of heat liberated during acrylate polymerization.

The chemical structures of alkoxyamines proposed for NMP contain N-alkoxy substituents and are similar to sterically hindered amines (HALS), a class of compounds with which Ciba Specialty Chemicals is very familiar from its light stabilizer business (see Fig.1, TINUVIN 123). Consequently, Ciba Specialty Chemicals' focus for industrial implementation of controlled free radical polymerization was on nitroxide-mediated radical polymerization (NMP), building on a long-standing chemical expertise.

To begin with, several sterically hindered alkoxyamines were prepared [2326]. Typical examples are shown in Fig. 8, structures 2-5. They all produce the desired nitroxides in situ by homolytic cleavage of the NO-C bond.

Subsequently, these compounds have been evaluated in the controlled synthesis of acrylic block copolymers such as compound 6 shown in Fig. 9. The synthesis proceeds in two steps. In the first step, the use of homo polymerization of n-butylacrylate to build block A is carried out in bulk using the alkoxyamine initiator 3 . For the second step, N,N-dimethylaminoethyl acrylate is added to build block $\mathrm{B}$. This reaction sequence is exceptionally robust and a specific feature of 'living' NMP reactions is that they can be shut down and restarted at will, depending primarily on temperature.

The resulting copolymers showed excellent results as pigment dispersants. The different polarities of the monomers incorporated in blocks A and B impart pronounced amphiphilic character to compound 6. Products with similar structures were introduced to the market in 2003 $\left(\mathrm{EFKA}^{\circledR} 4300\right.$ and $\left.\mathrm{EFKA}^{\circledR} 4330\right)$ [27][28]. The tailor-made polymer structures enable specific interaction with the pigment particles, providing efficient de-agglomeration and stabilization in a paint formulation, resulting in improved rheology and color development (Fig. 10). Their well-defined molecular weights, with narrow molecular weight distribution, can only be achieved by carefully controlled free radical polymerization, in this specific case by NMP.

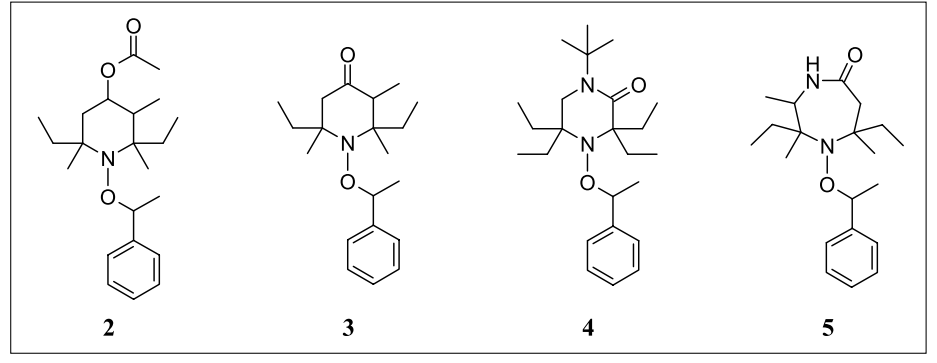

Fig. 8. Ciba alkoxyamine initiators for nitroxide mediated polymerization of acrylates

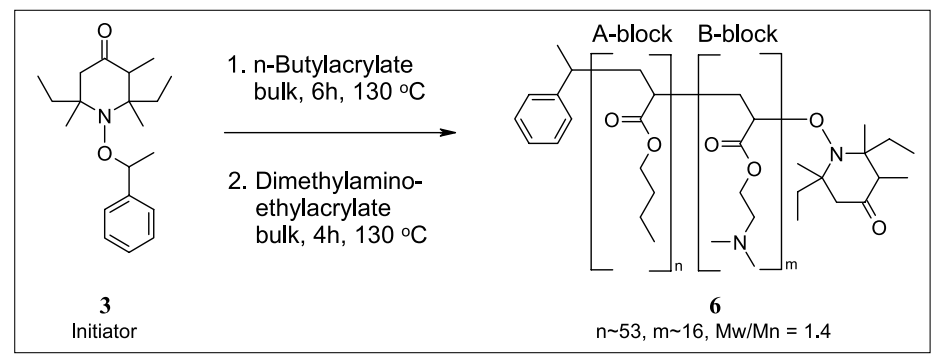

Fig. 9. Amphiphilic acrylate A-B block copolymer 6 prepared by NMP using initiator 3

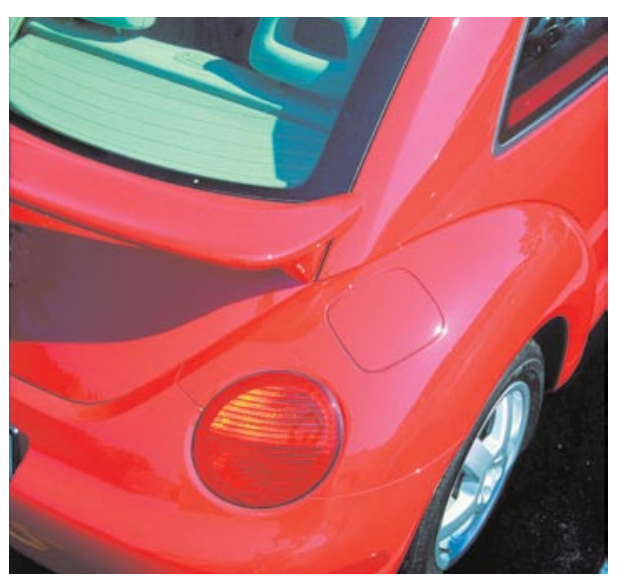

Fig. 10. Superior pigment-dispersing properties ensure improved pigment stabilization and rheology, and more uniform coloration

The large amount of heat liberated during the polymerization reaction was controlled by ingenious chemical engineering and equipment design. All of the accumulated know-how allows commercial production of AB-block copolymers in a safe, efficient, and reproducible way. Promising new products such as water-based dispersants, tailor-made dispersants for solventbased or powder coatings, rheology modifiers, flow and leveling agents as well as macromonomers and comb-copolymers [29] are in the pipeline.

\subsection{New Products for Rheology Control of Polypropylene (Peroxide Substitutes)}

The thermal homolysis of the NO-C bond in the hindered alkoxyamines, gener- ating persistent nitroxyl and reactive $\mathrm{C}$-centered radicals, is the basic principle of living Nitroxide Mediated radical Polymerization (NMP), as discussed in Section 3.1. In the course of the extensive studies with nitroxides and their precursors, a fundamentally different behavior of sterically hindered $\mathrm{N}$-acyloxyamines has been observed compared to $\mathrm{N}$-alkoxyamines. In fact, quantum chemical calculations [30] predict that the $\mathrm{N}-\mathrm{OCOMe}$ bond in these compounds, e.g. compound 7 in Fig. 11, is weaker (37.7 $\mathrm{kcal} / \mathrm{mol}$ ) than the NO-COMe bond (48.1 $\mathrm{kcal} / \mathrm{mol}$ ). Consequently, thermal cleavage of $\mathrm{N}$-acyloxyamines should produce different radicals compared to alkoxyamines, namely aminyl and acyloxy, as shown in Fig. 11. Consistent with this is the observation that $\mathrm{N}$-acyloxyamines act as efficient radical initiators [31], but in contrast to alkoxyamines, the polymerization is not living.

The scientific expertise gained from all of these radical reactions triggered curiosity and inspired Ciba Specialty Chemicals scientists to look for commercial applications of $\mathrm{N}$-acyloxyamines, for example in their capacity to act as thermal radical generators similar to peroxides.

An important commercial use of peroxides is in the controlled degradation of high molecular weight polypropylene (PP) to products with lower molecular weight and narrower molecular weight distribution. This process is usually done in an extruder at elevated temperatures by adding peroxides. Peroxide-free operations are desirable from the perspective of handling, safety and improved product quality. It could be 


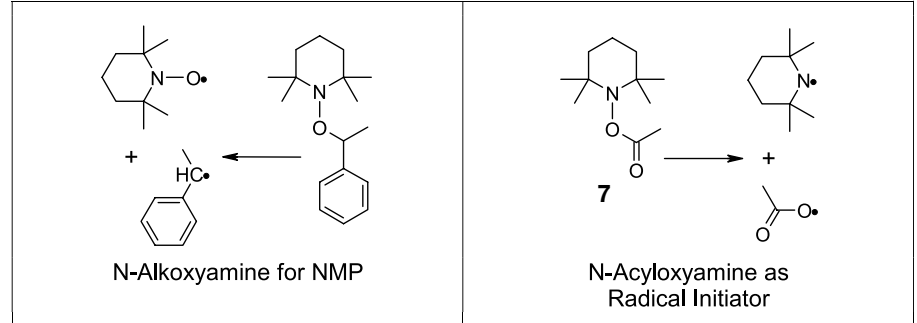

Fig. 11. Thermal cleavage of alkoxyamines (left) and $\mathrm{N}$-acyloxyamines (right)

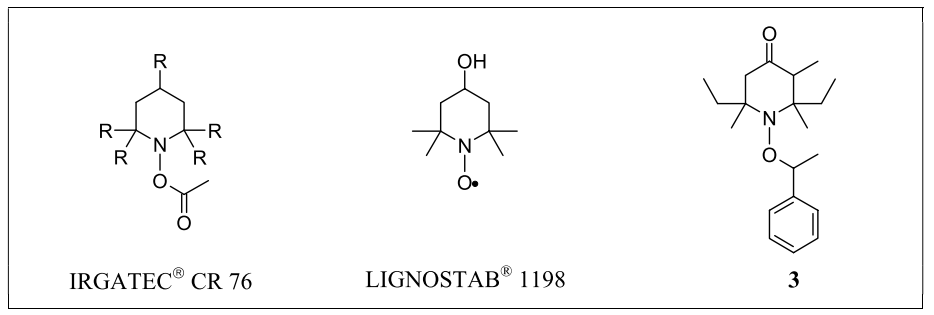

Fig. 12. Structures of HALS derivatives for applications beyond light stabilization

demonstrated that $\mathrm{Ciba}^{\circledR}$ IRGATEC $^{\circledR} \mathrm{CR}$ 76 [32], a concentrate containing a sterically hindered $\mathrm{N}$-acyloxyamine as active substance, fulfils the required product profile in an ideal way by showing a very high efficiency at processing temperatures above $250{ }^{\circ} \mathrm{C}$; typical conditions for manufacturing PP fiber grades. The performance of IRGATEC $^{\circledR}$ CR 76 polymer modifier can reach an increase of factor 4 to 5 at 290 ${ }^{\circ} \mathrm{C}$, compared to state-of-the-art peroxides (e.g. 2,5-dimethyl-2,5-di-tert.-butylperoxyhexane). Since no peroxide is used, several inherent disadvantages of the peroxide process such as discoloration, odor or smoke are eliminated or considerably reduced. In addition, the long-term thermal stability of the obtained PP at the same antioxidant level is clearly increased, due to the fact that the HALS fragment stays in the polymer and contributes as a stabilizer.

HALS structures are of paramount importance in the light stabilizer field, as shown in Section 2.1. Ciba Specialty Chemicals has been very successful in extending this technology platform into unique HALS derivatives allowing completely new applications such as polymerization regulators (Section 3.1) and peroxide substitutes described here. The structures of such HALS derivatives are summarized in Fig. 12.

\subsection{Next Generation Clarifier for Polypropylene}

Seeing more clearly through plastic, at first glance, might not register as a particularly important topic. However, as consumers we are faced every day with decisions where we wish we did have a clearer view of the packaged goods we are buying - especially when it comes to fresh foods such as meat, fruits and vegetables.
Homo- and copolymers of isotactic polypropylene (PP) are constantly gaining significance in packaging such as DVD boxes, kitchen ware, medical/sterilizable pouches, to name just a few examples [33][34]. The employed polymer grades are tailor-made and many contain nucleating agents - such as sodium benzoate, salts of phosphate esters or higher carboxylic acids - in order to provide polymers with enhanced stiffness, reduced warpage and/ or better economics during processing [35]. Due to the fact that PP is a semi-crystalline polymer, nucleation is a key concept in optimizing crystallinity and, hence, mechanical and optical properties. Most of the PP random copolymers are nucleated with clarifiers, a peculiar class of nucleating agents that also enhance transparency and the gloss of finished articles [36]. Several sorbitol bis-acetals have become industry standards over the years, despite their drawbacks with regard to thermal and chemical integrity, volatility and organoleptics.

A novel clarifier was recently launched $\left(\right.$ Ciba $^{\circledR}$ IRGACLEAR $^{\circledR}$ XT 386), meeting the market need for improvements [37][38]. The very low dosing of this product along with its extraordinary thermal and hydrolytic stability allow its use in any melt processing technology of PP, so that improved materials become accessible with retained aesthetics and mechanics even after regrind and recycle operations. Effective concentrations require only $150-200 \mathrm{ppm}$, roughly one tenth of the typical sorbitol loadings, and feature superior stability, organoleptic neutrality and low risk of volatility or migration. Main applications of IRGACLEAR XT 386 clarifier include PP for injection and blow-molding. Some classical examples are shown in Fig. 13. Its unprec-

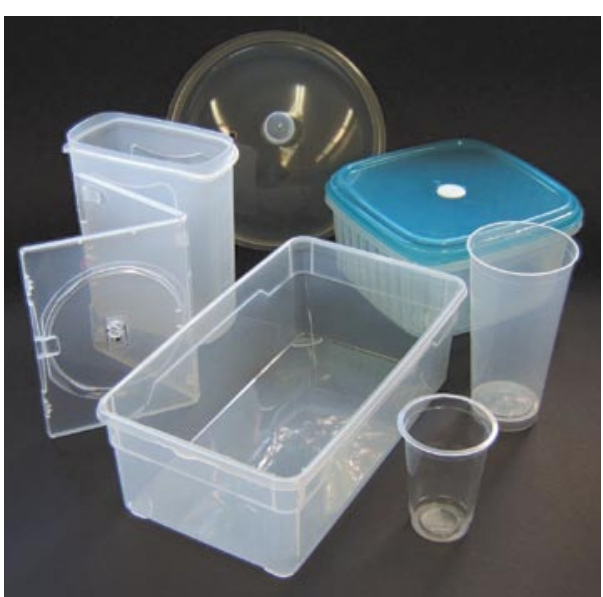

Fig. 13. Polypropylene articles clarified with $\mathrm{Ciba}^{\circledR}$ IRGACLEAR ${ }^{\circledR}$ XT 386

edented property spectrum may open further applications, for example PP extrusion processes, where conventional clarifiers are hardly applicable.

The development of IRGACLEAR XT 386 clarifier is based on interdisciplinary collaboration of Ciba Specialty Chemicals and academia. Partnerships with the teams of Prof. H.-W. Schmidt, University Bayreuth/Germany and Prof. P. Smith at the ETH Zürich/Switzerland enabled these outstanding academic institutions to link their expertise in molecular design and material science with industrial needs.

Entirely new approaches were taken at the ETH to study mechanisms and primary functions of nucleating agents. Starting from the seemingly 'magic effect' of sorbitol clarifiers in a PP matrix, a new basis was established by their fundamental phase behavior [39], and this was correlated with their impact on the macroscopic properties of nucleated PP [40]. It became evident from these findings that clarifiers - in contrast to nucleating agents - dissolve completely during melt processing, and recrystallize upon cooling into fibrillar network structures [39][41]. A very high density of nuclei with homogeneous distribution is thereby generated, leading to the extremely fine morphology of the matrix and ultimately the high transparency and see-through clarity of such polypropylenes.

On the other hand, tremendous synthetic efforts at the University Bayreuth laid the groundwork for a versatile structural 'database' of compounds, which allowed for systematic elucidation of structure-property relations of clarifiers and correlations with macroscopic optical and mechanical properties of nucleated PP [42]. The physicochemical approach, which had explained the efficiency of sorbitol bis-acetals, could subsequently be translated back into optimized molecular architectures of aromatic tris-amides, the structural family of IRGACLEAR $^{\circledR}$ XT 386 clarifier. Our investiga- 
tions of these highly versatile tris-amides have opened a variety of new, seemingly non-related polymer applications reaching far beyond the original targets. The progress of this ongoing work will be published in due course.

\subsection{Effect Pigments}

The "bending" of light to create beauty is a natural attribute of butterfly wings, insect shells, bird feathers, fish skins, sea shells and of course many minerals, for example opals [43]. Such materials allow light to be interpreted by the human eye in a similar way to a musical symphony that is interpreted by the ears: the sum of light with different wavelength, or the sound of every single instrument picked up, creates the total experience perceived. In the above-mentioned examples, nature does not produce color by adding a colorant, but rather by playing creatively with physical phenomena associated with light, such as reflection, diffraction, and absorption by layered structures. The structures are designed to affect the propagation of electromagnetic waves (light) and compose color thereafter by interference.

'Effect pigments' are man-made imitations of nature. Platelets composed of several coplanar layers with different indices of refraction allow reflection, diffraction and absorption of light and, hence, the creation of a wide range of colors and visual effects by interference [44]. Color shade, intensity and purity of properly designed effect pigments may even change with the viewing angle, adding another spectacular dimension to color.

Sheet silicates like micas (natural muscovite or synthetic fluorophlogopite) are attractive starting materials for effect pigments. They are first exfoliated and milled in order to get the isolated platelets of 20-25 microns in diameter and $100-500 \mathrm{~nm}$ in thicknesses. In the second step homogeneous coplanar layers of $\mathrm{TiO}_{2}$, with a thickness of about $40 \mathrm{~nm}$, are applied on both sides in a chemical deposition process in solution, followed by heat treatment. Each individual platelet behaves now as three-layer optical system $\left(\mathrm{TiO} / \mathrm{mica} / \mathrm{TiO}_{2}\right)$ producing color. This color depends not only on the thickness of the $\mathrm{TiO}_{2}$ layers but also on the thickness of the mica core. Since the core produced from natural mica varies in thickness, various colors are emitted by the individual platelets. The resulting optical effect is a special white, namely pearlescent white, the same as observed with natural pearls. Colored products are obtained by increasing the $\mathrm{TiO}_{2}$ layer thickness to $>50 \mathrm{~nm}$. Ciba Specialty Chemicals has formed a Joint Venture, Zhejiang Ruicheng Effect Pigment Co., to manufacture these pearlescent pigments. They meet today's demand

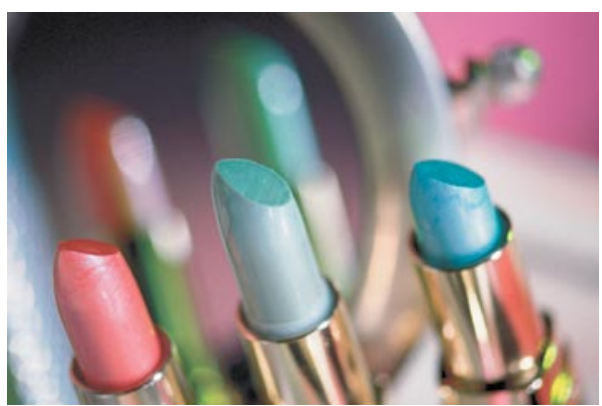

Fig. 14. Pearlescent pigments give subtle color effects to lipsticks both inside and outside

for subtle pearlescent effects in coatings, plastics, inks, cosmetics (Fig. 14) and paper.

Another range of effect pigments is based on metallic flakes that show very high reflectivity (higher than aluminum flakes used for metallic shades in automotive coatings) and, hence, a mirror-like metallic effect. The acquisition of Wolstenholme's METASHEEN ${ }^{\circledR}$ product line opened the doors to this technology for Ciba Specialty Chemicals in 2005. METASHEEN ${ }^{\circledR}$ pigments are high-reflectance aluminum platelets produced in a sophisticated vacuum metallization process. They offer the printing industry fantastic new design options and a cost-effective alternative to metallized substrates and foiling.

None of the above-described systems will lead to colors that depend on the observation angle (gonio-chromaticity). Such products would similarly be based on multilayered coplanar platelets, but their thickness must be much more uniform. This is obviously not possible with natural mica, having a natural thickness distribution of $100-500 \mathrm{~nm}$, as discussed above.

Ciba Specialty Chemicals' own research activities in effect pigments focused consequently on developing new and cost-effective ways to produce very uniform multilayer structures allowing a broad spectrum of color effects, including angle-dependent colors. A new way of producing such materials consists of subliming a metal oxide layer under high vacuum onto a water-soluble release layer, which is itself set on a closed-loop running metal band [45]. This setup leads to perfectly uniform layers that can be used as core materials. Subsequent build-up of additional coplanar layers, applying new deposition technologies, leads to the desired effect pigments with well-defined colors that depend on the viewing angle. Angledependency, shade, intensity and purity of the color depend on the relative thickness of each layer, as long as the thickness of the core is of the same order of magnitude as about half the wavelength of the visible light, meaning 200-500 nm. Realization of multilayered structures, consisting of layers featuring refractive index gradi- ents within individual layers, will help to further improve color purity of effect pigments [46].

\section{Outlook}

Ciba Specialty Chemicals is committed to sustaining and further developing the technical core competencies and product ranges it currently offers to the market. On top of this, progress in enabling sciences such as nanotechnology and biotechnology, together with new technologies entering the markets in digital imaging, electronics, energy management, diagnostics and security, will offer outstanding opportunities for new developments.

Ciba's nanotechnology R\&D is focusing on thin layers, as described in Section 3.4 , and on inorganic and organic nanoparticles. New products and materials are in development for coatings and plastics to increase hardness or scratch resistance, water- and dirt-repellency or to alter electrostatic properties. Know-how in nanotechnology has already been applied during the development of UV absorbers for cosmetics (TINOSORB ${ }^{\circledR} \mathrm{M}$, mentioned in Section 2.1). This product consists of a micronized hydroxyphenyl-benzotriazole derivative. The small particle size allows the formulation of sunscreens with high sun protection factors, long-lasting protection, and optimal skin feel [8]. Nanocolloids (NANOTOPESTM) from Ciba deliver anti-aging compounds more efficiently into lower layers of the skin $\left(\mathrm{Ciba}^{\circledR}\right.$ TINODERM $^{\circledR} \mathrm{A}$ and TINODERM $\left.{ }^{\circledR} \mathrm{E}\right)$. And, as already mentioned in Section 2.2, color filters for displays are based on nanosized pigments.

The vision behind Ciba's biotechnology activities is the integration of biologi$\mathrm{cal} /$ biocatalytic research with material sciences for the development of value-added novel products and the implementation of biological production processes for key intermediates based on existing or renewable raw materials.

Organic electronics and optoelectronics are setting new trends for potential growth markets. These new technologies require the development of a complete range of novel materials. Some organic materials might be applied by vapor deposition methods, as their inorganic counterparts today, but others will be applied in a solution process, opening-up the fascinating world of printable electronics. For instance, specific organic semiconductor materials can be used as functional organic 'inks' to allow direct printing of integrated circuits, forming radio-frequency identification devices (RFIDs). Other emerging applications are in the areas of printable organic solar cells and photodiodes. 
Ciba is already supplying specialty materials for OLEDs (organic light emitting diodes). New tailor-made materials will make it possible to prepare flexible or even rollable displays, a further development compared to the planar and rigid screens available today. Efficiency improvements in converting electrical energy into light, together with significantly longer lifetimes of such devices, will allow the use of OLED technology for lighting.

Embarking on these technologies will be a fascinating challenge, also for Ciba's scientists. It will require interdisciplinary collaboration between chemists, biologists, molecular biologists, physicists and material scientists. This kind of research will no longer be possible within a single organization. Therefore, Ciba will strengthen the concept of 'open innovation'. This means maintaining strong internal $R \& D$ and connecting it with the best research institutes, innovative customers and other technology incubators. This will increase creativity and allow accelerated development of breakthrough products, making Ciba Specialty Chemicals' vision reality: We create effects to improve the quality of life.

\section{Acknowledgements}

The authors thank Patrice Bujard, Kurt Dietliker, Vadiraj Ekkundi, Thomas Gerlach, Malcolm Hawe, Rino Hüsler, Klaus Stoll and Peter Nesvadba for their contributions to this article.

Received: December 3, 2006

[1] K. Schwarzenbach, B. Gilg, D. Müller G. Knobloch, J.-R. Pauquet, P. Rota-Graziosi, A. Schmitter, J. Zingg, E. Kramer, F. Gugumus, in 'Plastics Additives Handbook', Ed. H. Zweifel, Hanser Publishers, Munich, 2001, p. 1, 141.

[2] A. Valet, in 'Light Stabilizers for Paints', Ed. U. Zorll, Vincentz Verlag, Hannover, 1997, p. 13.

[3] H. Zweifel, in 'Stabilization of Polymeric Materials', Ed. U.W. Suter, Springer, Berlin Heidelberg, 1998, p. III.

[4] P.C. Hamblin, P. Rohrbach, Petroleum and Coal 1998, 40, 156.

[5] D. Rogez, paper presented at the 2nd Wood Coatings Congress, The Hague, 2000.

[6] R. Pfaendner, Kunststoffe 2006, 96, 64.

[7] D. Hüglin, J. Lupia, T. Ehlis, Cosmetic \& Toiletries 1998, 319.

[8] B. Herzog, D. Hüglin, E. Borsos, A. Stehlin, H. Luther, Chimia 2004, 58, 554.

[9] C. Holland, American Ink Maker 2000, 14.

[10] W. Herbst, K. Hunger, 'Industrial Organic Pigments', Wiley-VCH, Weinheim, 3rd Ed., 2004.

[11] O. Wallquist, in 'High Performance Pigments', Ed. H.M. Smith, Wiley-VCH, Weinheim, 2002, p. 159.

[12] A. Iqbal, F. Herren, O. Wallquist, in 'High Performance Pigments', Ed. H.M. Smith, Wiley-VCH, Weinheim, 2002, p. 231.
[13] G.M. Moody, P.I. Norman, in 'Solid/Liquid Separation - Scale-Up of Industrial Equipment', Ed. R.J. Wakeman, E.S. Tarleton, Elsevier Advanced Technology, Oxford, 2005, p. 38.

[14] M.A. Hubbe, 'Emerging Technologies in Flocculation', PIRA Int. Ltd., 2005.

[15] J. Liu, Paper Technology 2005, 31.

[16] D.S. Honig, Nordic Pulp and Paper Research Journal 2000, 15, 536.

[17] K. Dietliker, in 'Photoinitiators for Free Radical, Cationic \& Anionic Photopolymerization', Vol 3 of the series Chemistry \& Technology of UV \& EB formulations for Coatings, Inks and Paints, Ed. G. Bradley, Wiley/SITA Series in Surface Coating Technology, London, 1998, p. 61, 479.

[18] K. Dietliker, 'A Compilation of Photoinitiators commercially available for UV today', SITA Technology Limited, Edinburgh, 2002

[19] K. Dietliker, R. Hüsler, J.-L. Birbaum, S. Ilg, S. Villeneuve, K. Studer, T. Jung, J. Benkhoff, H. Kura, A. Matsumoto, H. Oka, Prog. Org. Coat. 2007, 3, to be published.

[20] T. Jung, P. Simmendinger, W. Topisch, Eur. Coat. J. 2005, 4, 138.

[21] O.W. Webster, Science 1991, 887.

[22] G. Moad, D.H. Solomon, 'The Chemistry of Radical Polymerization', Elsevier, 2006.

[23] P. Nesvadba, L. Bugnon, R. Sift, J. Polym. Sci. Part A: Polym. Chem. 2004, 42 , 3332.

[24] H. Fischer, A. Kramer, S.R.A. Marque, P. Nesvadba, Macromolecules 2005, 38, 9974.

[25] S.R.A. Marque, J. Sobek, H. Fischer, A. Kramer, P. Nesvadba, W. Wunderlich, Macromolecules 2003, 36, 3340.

[26] H. Fischer, S.R.A. Marque, P. Nesvadba, Helv. Chim. Acta 2006, 89, 2330.

[27] C. Auschra, E. Eckstein, R. Knischka, F. Pirrung, P. Harbers, Eur. Coat. J. 2006 , 04, 26.

[28] C. Auschra, E. Eckstein, R. Knischka, P. Nesvadba, Asia Pasific Coat. J. 2003, 20.

[29] A. Mühlebach, F. Rime, J. Polym. Sci., Polym. Chem. Ed. 2003, 41, 3425.

[30] P. Nesvadba, unpublished results: estimated at B3LYP/6-311+G(d,p)// B3LYP/6$31 \mathrm{G}(\mathrm{d})+$ ZPE level of theory.

[31] M. Roth, R. Pfaendner, P. Nesvadba, M.-O. Zink, WO Patent No. 01/90113, 2001.

[32] M. Roth, A. Schneider, Nonwovens Report International 2005, 40.

[33] C. Smith, European Plastic News 2005, 22.

[34] M. Gahleitner, M. Wacholder, Kunststoffe 2005, 12, 47.

[35] J. Kurja, N. Mehl, in 'Plastics Additives Handbook', Ed. H. Zweifel, Carl Hanser Verlag, Munich, 2001, p. 949.

[36] C. Marco, G. Ellis, M.A. Gómez, J.M. Arribas, J. Appl. Polym. Sc. 2002, 84, 2440.
[37] M. Freemantle, Chem. Eng. News 2005, 83, 10.

[38] P. Walter, paper presented at the Polypropylene 2006, 15th Annual World Congress, Zürich, 2006.

[39] M. Kristiansen, M. Werner, T. Tervoort, P. Smith, M. Blumenhofer, H.-W. Schmidt, Macromolecules 2003, 36, 5150.

[40] M. Kristiansen, T. Tervoort, P. Smith, H. Goossens, Macromolecules 2005, 38 10461.

[41] T. Kobayashi, T. Hashimoto, Bull. Chem. Soc. Jpn. 2005, 78, 218.

[42] M. Blomenhofer, S. Ganzleben, D. Hanft, H.-W. Schmidt, M. Kristiansen, P. Smith, K. Stoll, D. Mäder, K. Hoffmann, Macromolecules 2005, 38, 3688 .

[43] R.D. Meade, J.N. Winn, 'Photonic Crystal: Molding the Flow of Light', Princeton University Press, Princeton, 1995.

[44] R. Pfaff, Chem. Rev. 1999, 99, 1963.

[45] P. Bujard, H. Hoppe, paper presented at the ICN+T, Basel, 2006.

[46] P. Bujard, N. Bonnard, R. Takahashi, US Patent No. 5855660, 1999. 